\title{
A relação entre os sinais de pontuação e o processamento de leitura de alunos concluintes do Ensino Médio
}

The relationship between punctuation marks and the reading processing of high School Students

\section{Simone Aparecida Almeida}

\section{Aline Alves Fonseca}

Universidade Federal de Juiz de Fora - UFJF - Juiz de Fora - Minas Gerais - Brasil

\begin{abstract}
$\longrightarrow$
Resumo: Este artigo é resultado de um dos experimentos realizados em uma pesquisa de Mestrado que busca investigar se há uma relação entre produção e percepção prosódica dos sinais de pontuação na leitura em voz alta e a compreensão do texto. Para isso, manipulamos ausência/presença de sinais de pontuação no textoestímulo, a fim de observar a influência desse fator na produção e na compreensão. Os resultados sugerem que a ausência de sinais de pontuação pode influenciar a produção da leitura em voz alta e a retenção lexical, mas não a compreensão global do texto.
\end{abstract}

Palavras-chave: Leitura. Pontuação. Prosódia. Compreensão.

Abstract: This paper is the result of an experiment carried out in a Master's research study that investigates whether there is a relationship between prosodic perception and production of the punctuation marks in reading aloud and the comprehension of the text. For this, we manipulated the absence/presence of punctuation marks in the stimulus text, in order to observe the influence of this factor on production and comprehension. The results suggest that the absence of punctuation marks can influence the production of reading aloud and lexical retention, but not the overall comprehension of the text.

Keywords: Reading. Punctuation. Prosody. Comprehension. 


\section{Introdução}

O presente trabalho de pesquisa tem como tema a relação entre pontuação, leitura $e$ compreensão de textos. Como objeto de estudo, tomamos os sinais de pontuação que usamos na escrita da Língua Portuguesa, para observar como se dá a produção desses sinais na leitura em voz alta e na escrita, a fim de verificar a relação entre essa produção e a compreensão do texto. Sob o viés psicolinguístico, investigamos a influência dos sinais de pontuação, enquanto recursos da escrita, no processamento de leitura.

Ao iniciarmos os estudos sobre esse tema, deparamo-nos com a concepção de que a pontuação é um sistema de recursos gráficos que serve para facilitar a leitura e a compreensão de textos, concepção esta defendida por gramáticos como Bechara (2009) e linguistas como Cagliari (1989) e Pacheco (2003). Bechara (2009) afirma que os sinais de pontuação são fundamentais no processo de comunicação e se impõem como objeto de estudo e de aprendizagem.

Cagliari (1989) e Pacheco (2003) pressupõem que os recursos gráficos presentes no texto seriam pistas prosódicas sobre a maneira como pronunciamos e como segmentamos a fala, facilitando a concatenação das palavras em unidades fonológicas, sintáticas, semânticas e discursivas para que se possa recuperar integralmente o que está escrito. No entanto, Bernardes (2002) apresenta uma crítica interessante em relação a essa concepção. De acordo com a autora, "a naturalidade com que se atribui papel facilitador à pontuação merece ser interrogada, sobretudo porque há sistemas de escrita que não a utilizam [...]" (BERNARDES, 2002, p.36).

Diante das controvérsias em relação à concepção discutida, as perguntas que deram origem à esta pesquisa são: (I) em que medida a ausência de pontuação nos textos influenciaria a leitura em voz alta e a compreensão? (II) como se dá a relação entre a segmentação na escrita, a partir da marcação gráfica de pontuação, e o fraseamento prosódico na leitura em voz alta?
Com o objetivo de verificar se há uma relação entre a produção prosódica dos sinais de pontuação na leitura em voz alta e a compreensão do texto, consideramos fundamental para a investigação as seguintes teorias: a hipótese dos sinais de pontuação como marcadores prosódicos gráficos (MPGs), de Cagliari (1989), a teoria da Fonologia Prosódica de Nespor e Vogel (2007) sobre a organização prosódica mental da fala e a Hipótese da Prosódia Implícita de Fodor (2005). A partir da articulação dessas bases teóricas, propomos a seguinte hipótese de trabalho: há uma prosódia implícita da fala que se projeta na leitura, guiando a segmentação e a organização dos constituintes prosódicos e sintáticos, facilitando o processamento linguístico e a compreensão do texto. Nesse sentido, mesmo que não haja marca gráfica, se for necessária uma pausa ou entoação, por exemplo, a produção ocorrerá oralmente, já que representamos mentalmente a fala em constituintes prosódicos e essa representação se projeta na leitura.

Para a testagem dessa hipótese, assim como para a realização dos objetivos do estudo, elaboramos um experimento de produção de leitura e compreensão. A seguir, apresentaremos brevemente, como arcabouço teórico, algumas reflexões sobre a apresentação do termo pontuação pelas gramáticas normativas do Português Brasileiro. Discutiremos a relação entre prosódia e pontuação a partir de teorias fonológicas e contribuições de pesquisas anteriores. Além disso, apresentaremos algumas considerações sobre leitura e processamento que são importantes para este trabalho. Na sequência, apresentamos a metodologia e os resultados do experimento. Por último, a partir das discussões dos resultados, apresentaremos algumas considerações em relação ao ensino da pontuação.

\section{Aporte teórico}

Nesta seção, apresentamos muito brevemente os estudos e teorias dos principais autores que nortearam nosso trabalho. As subseções estão organizadas de acordo com a temática abordada nos 
estudos resenhados que possuem relevância para a pesquisa em questão.

\subsection{Os sinais de pontuação}

O termo pontuação geralmente é definido em torno de suas propriedades e funções. Ao comparar a abordagem da pontuação em algumas gramáticas normativas do português brasileiro a partir dos anos 1960, percebe-se que a maioria das gramáticas analisadas não apresenta uma definição geral para o termo. Rocha Lima (1964) apresenta a prescrição de que os sinais de pontuação devem ser usados na tentativa de reconstituir as pausas rítmicas, assinaladas na pronúncia por entoações características assim como a melodia. Cunha e Cintra (2001) apresentam o termo a partir de sua finalidade: "a língua escrita não dispõe dos inumeráveis recursos rítmicos e melódicos da língua falada. Para suprir esta carência, ou melhor, para reconstituir aproximadamente o movimento vivo da elocução oral, serve-se da PONTUAÇÃO" (CUNHA E CINTRA, 2001, p. 643). Cegalla (2005) apresenta os sinais de acordo com sua tríplice finalidade; (I) assinalar as pausas e as inflexões da voz (a entoação) na leitura; (II) separar palavras, expressões e orações que devem ser destacadas; e (III) esclarecer o sentido da frase, afastando qualquer ambiguidade.

Apenas Bechara (2009) apresenta uma definição nos termos de Nina Catach em La Pontuaction (1994): "um sistema de reforço da escrita, constituído de sinais sintáticos, destinados a organizar as relações e a proporção das partes do discurso e das pausas orais e escritas. Estes sinais também participam de todas as funções da sintaxe, gramaticais, entonacionais e semânticas" (CATACH, 1994 apud BECHARA, 2009, p. 604).

Verifica-se, portanto, uma heterogeneidade na maneira de apresentar os sinais de pontuação, ora dando ênfase para a prosódia, ora para a sintaxe. Este fato que pode ser considerado uma influência negativa no processo de ensino-aprendizagem, uma vez que a multiplicidade de funções e de formas de apresentação dos sinais de pontuação apresentadas nas gramáticas tradicionais acaba por gerar confusões na apreensão das regras e, consequentemente, acarreta problemas para 0 processo. Além disso, as definições apresentam lacunas a respeito da relação entre linguagem oral e escrita, principalmente em relação às pausas, como se as pausas fossem sempre marcadas na escrita. $\mathrm{Na}$ próxima seção, apresentaremos alguns pressupostos teóricos que podem auxiliar na discussão sobre essa relação entre oralidade e escrita.

\subsection{Prosódia e sinais de pontuação}

Para esta pesquisa sobre sinais de pontuação, torna-se necessário primeiramente definir prosódia e entoação. A prosódia no âmbito da Fonologia trata de seus aspectos suprassegmentais: intensidade, duração, variação melódica e pausa. A entoação seria, então, um componente prosódico que diz respeito à variação melódica em um enunciado (FONSECA, 2008).

Para a análise prosódica de nossos dados, adotamos os pressupostos da Teoria da Fonologia Prosódica de Nespor e Vogel (2007). De acordo com essa teoria, há uma organização prosódica hierárquica inerente à estrutura da língua que faz parte da representação mental da fala. Nessa representação, haveria pedaços, isto é, constituintes prosódicos, formados de acordo com regras fonológicas e não-fonológicas, que se relacionam para formar um enunciado: sílaba, pé, palavra fonológica, grupo clítico, sintagma fonológico, sintagma entoacional e enunciado fonológico.

O constituinte mais relevante para este estudo é o sintagma entoacional, pois uma das questões é investigar como se dá a relação entre fraseamento e sinais de pontuação e é este o domínio de interface com a sintaxe e com a semântica, sobre o qual recai o contorno entoacional, cujas fronteiras coincidem com posições nas quais pausas são introduzidas na sentença.

Neste artigo, relacionamos as fronteiras de sintagma entoacional com as fronteiras marcadas 
pelos sinais de pontuação. Acreditamos que um dos recursos de representação da prosódia na língua escrita pode ser o sistema de sinais de pontuação, já que estes sinais de acordo com suas definições são usados para marcar relações prosódicas, sintáticas e semânticas nos textos escritos (CAGLIARI, 1989; PACHECO, 2003).

Em articulação com a Teoria da Fonologia Prosódica de Nespor e Vogel, consideramos relevante a hipótese da Prosódia Implícita (HPI), proposta por Fodor (2005). Vejamos a definição da HPI:

$\mathrm{Na}$ leitura silenciosa, um contorno prosódico default é projetado no estímulo e pode influenciar a resolução da ambigüidade sintática. Tudo mais permanecendo constante, o parser favorece a análise sintática associada ao contorno prosódico mais natural (default) para a construção. (FODOR, 2005, p. 96.)

De acordo essa hipótese, a análise sintática e a atribuição da prosódia podem estar intercaladas com 0 processamento prosódico dando prosseguimento ao processamento sintático de baixo nível e alimentando, mais tarde, as decisões sintáticas do parser, nosso processador mental. Uma decisão equivocada desse processador pode levar 0 leitor a um estranhamento ou um engano no momento da leitura, o chamado efeito Garden-Path, de acordo com a teoria de Frazier (1979). Tal estranhamento ocorre devido ao fato de o leitor assumir uma estrutura no início da análise e precisar de, em um determinado ponto da frase, abandonar a estrutura que havia previsto e construído até ali e reanalisar a frase.

Desde o surgimento da $\mathrm{HPI}$, as pesquisas sobre o papel da prosódia como importante pista no processamento de sentenças foram alavancadas, tanto na produção, quanto na compreensão de enunciados. A presente pesquisa busca evidências que vão além do processamento de sentenças. Investigamos, ainda que de forma preliminar, a HPI na produção prosódica dos sinais de pontuação na leitura e no processamento de textos.

$\mathrm{Na}$ interface entre prosódia, leitura e escrita, estudos mais antigos defendem que a função dos sinais de pontuação seja estritamente sintática e de organização textual (BALDWIN; COADY, 1978 apud PACHECO, 2003), enquanto outros, mais recentes, defendem que os sinais de pontuação são uma forma de representar variações prosódicas da fala, funcionando assim como marcadores prosódicos da escrita (CAGLIARI, 1989; PACHECO, 2003), ou ainda, como marcas linguísticas prosódicas que evidenciam a organização prosódica mental e a relação entre oralidade e escrita (SONCIN; TENANI, 2015).

\subsection{Leitura e Processamento}

Segundo Gabriel, Morais e Kolinsky (2016),há pelo menos duas acepções bastante aceitas entre os estudiosos da leitura: uma mais restrita (ler é estabelecer uma relação entre grafema e fonema, a partir da qual será possível a produção de significado); e outra no sentido ampliado (ler é estabelecer uma relação entre um símbolo (sons, cores, ícones, gestos, letras) e um significado). O que há de comum entre esses dois tipos de leitura é a capacidade cognitiva de lidar com símbolos, isto é, a capacidade simbólica, que se desenvolve a partir da interação do indivíduo com os símbolos presentes no meio em que está inserido e permite a produção de significados.

Há também um consenso entre estudiosos e pesquisadores de que a leitura influencia no aprendizado da escrita. Contudo, é importante destacar que há especificidades em cada um desses processos. E para compreender melhor cada processo é necessário compreender as semelhanças e diferenças entre linguagem escrita e linguagem oral. Por exemplo, operações cognitivas complexas, como aprendizagem, compreensão, interpretação, estabelecimento de inferências, uso adequado de expressões mais ou menos literais ou metafóricas são comuns tanto à linguagem oral quanto à escrita. Porém, a forma como se dá a interação falanteouvinte e leitor-escritor são distintas (GABRIEL; MORAES; KOLISKY, 2016). E ainda, estudos cognitivistas e conexionistas dos últimos anos defendem essa relação reforçando a importância da 
exposição, do input, da frequência, da regularidade, da emoção, da atenção, dentre outros, para o desenvolvimento tanto da leitura quanto da escrita (BORBA; PEREIRA; SANTOS, 2014).

Quanto ao processamento, os estudos sobre leitura têm evidenciado a relação entre leitura, memória e cognição. Durante o processamento textual, o leitor proficiente faz uso de um processamento interativo, isto é, de estratégias diversas que vão desde a decodificação da palavra até a influência do conhecimento de mundo, em um movimento ascendente, do tipo bottom-up, ou em movimento contrário, envolvendo um tipo de processamento top-down, descendente (KLEIMAN, 2008). Já os leitores aprendizes, segundo Dehaene et al. (2015), usam predominantemente o processamento bottom-up já que estão em processo hierárquico de construção do conhecimento e necessitam de tempo e experiência para construir na memória de longo prazo as estruturas que possibilitarão o processamento preditivo, top-down (DEHAENE et al, 2015 apud GABRIEL; MORAES; KOLINSKY, 2016).

Portanto, o desenvolvimento da escrita e da leitura evidencia um conjunto de habilidades complexas que requer do indivíduo a utilização de diferentes processos cognitivos. Assim, através da prática da leitura, o sujeito se torna proficiente e a tarefa de decifrar o código escrito vai sendo automatizada de tal forma que o leitor não vê mais as letras, e sim os significados a que elas se remetem.

\section{Experimento de leitura e compreensão}

Nesta seção apresentamos a tarefa experimental que desenvolvemos a fim de testar se a presença ou a ausência dos sinais de pontuação em um texto podem influenciar o desempenho de leitores concluintes do ensino médio e, ainda, se podem influenciar a compreensão do texto. Dividimos a apresentação do experimento em Metodologia, Resultados da tarefa de leitura e Resultados da tarefa de compreensão.

\subsection{Metodologia}

Para alcançar os objetivos da pesquisa reportada neste artigo, foi elaborado um experimento de leitura e compreensão. O experimento buscou (I) observar as variações melódicas decorrentes e não decorrentes dos sinais de pontuação na leitura em voz alta e compará-las com a marcação gráfica presente no texto-estímulo; (II) identificar características entoacionais representadas pelos sinais de pontuação no texto escrito; e (III) verificar o quanto a ausência de pontuação ou a presença de uma pontuação equivocada poderiam influenciar na leitura em voz alta e na compreensão dos textos.

Para esse experimento, escolhemos um texto do gênero notícia, publicado no website de notícias intitulado G1 (a referência completa está na seção de Referências deste artigo). A escolha do texto foi motivada por se tratar de um gênero textual com características de objetividade e cuja estrutura textual possibilita a ocorrência de vários encaixamentos, consequentemente, a ocorrência de mais sinais de pontuação, como vírgulas. Foram feitas algumas adaptações para que o texto chegasse a um tamanho ideal para a atividade experimental. Em sua versão final, o texto passou a apresentar 39 sinais de pontuação, sendo que o ponto final do texto foi considerado apenas para análise das marcações gráficas e desconsiderado para a análise das marcações prosódicas da leitura em voz alta, por ser uma marca de fronteira de final absoluto do texto. A seguir, apresentamos o texto já adaptado, com a enumeração dos sinais de pontuação que foram considerados em nossa análise. 
Um menino de nove anos foi agredido na saida da escola, por colegas de classe e teve de ser hospitalizado.2 Ele teve uma lesão na coluna cervical e vai precisar de um colete ortopédico por uns dias. 3

O garoto,4 que é gago,s recebeu socos e pontapés. 6 na cabeça e nas costas. $z$ de pelo menos cinco meninos. .8 todos com menos de 12 anos. 9 Após o ocorrido.10 0 garoto foi para casa.11 mas não quis revelar à mãe as agressões.12 No dia seguinte, 13 no entanto, 14 com muitas dores, is foi levado a um hospital da cidade. 16 Os exames clínicos revelaram lesões sem extensões graves. 17

A Policia Civil apura o caso.18 Segundo a delegada responsável.19 os garotos apontados como os autores da agressão deverão comparecer com os pais na semana que vem para prestar depoimento ${ }_{20}$ Se for comprovada a participação dos meninos.21 eles poderão cumprir medidas socioeducativas previstas no estatuto da criança e do adolescente. $22 \mathrm{~A}$ delegada afirmou que há relatos de que o garoto.23 por ter problemas na fala.24 vinha sofrendo humilhaçōes.25 0 que caracteriza a prática de bullving 26 , a violência fisica ou psicológica entre colegas de forma repetitiva. 27

Ao jornal local.28 a mãe do garoto disse que o filho caiu no chão e que foi chutado pelos colegas. 29 Ele disse: 30 "Ah mãe, 31 me deu murro na cabeça.,32 me deu chute.33 eu caí no chão".34O menino está em repouso no hospital.35 Segundo o último boletim médico, 36 ele está lúcido,37 recebendo analgésicos, e tem alta prevista para breve 38

A secretaria de Educação do Estado disse que foi aberta uma apuração preliminar para averiguar a denúncia de agressão entre os alunos da escola. 39

Figura 1: Texto adaptado com os sinais de pontuação enumerados

Em relação à compreensão, trata-se de um texto simples, sem palavras complexas ou raras. Consideramos, então, que o texto exige um nível de proficiência de leitura correspondente às habilidades de leitores que estão no ensino médio. Apesar de não se tratar de uma leitura complexa, algumas inferências devem ser feitas por parte do leitor para que a interpretação do texto seja satisfeita e queremos verificar se as condições experimentais influenciariam nos resultados do teste de compreensão.

Participaram dessa tarefa 22 sujeitos, sendo que 20 eram alunos do $3^{\circ}$ ano do ensino médio. Os outros 2 sujeitos, escolhidos como controle devido ao alto nível de escolaridade e consequentemente maior nível de proficiência em leitura esperado, eram professoras da Educação Básica com título de Doutorado em Linguística. Divididos em dois grupos, os participantes realizavam as seguintes tarefas: i) o grupo chamado CP (Com Pontuação) lia silenciosamente um texto com a pontuação original e lia uma segunda vez para gravação; ii) o grupo chamado SP (Sem Pontuação) lia o mesmo texto, porém, apresentado sem pontuação e sem a divisão do texto em parágrafos, com todas as palavras em letra minúscula, pontuava o texto e lia a segunda vez para gravação. Após cada leitura, os participantes de ambos os grupos respondiam um bloco de questões de compreensão, o primeiro bloco com perguntas no nível da palavra e o segundo com perguntas no nível da proposição.

Para a gravação dos itens experimentais, foi utilizado um gravador de alta resolução da marca SONY, modelo PCM-D50 e para a análise acústica dos itens experimentais coletados no experimento 1 , foi utilizada a técnica de oitiva e análise acústica auxiliada pelo programa PRAAT (BOERSMA \& WEENIK, 2013).

A aplicação do questionário de compreensão ocorreu através do programa DMDX (FORSTER \& FORSTER, 2002) e as instruções eram passadas tanto oralmente quanto por escrito na tela do computador. Após a leitura das questões, o participante deveria esperar aparecer as opções de resposta, SIM ou NÃO, VERDADEIRO ou FALSO. Contabilizamos nesta tarefa as respostas dadas pelos participantes para as questões apresentadas e o tempo de reação gasto na escolha da resposta. Para este artigo, no entanto, apresentaremos apenas os resultados de escolha das respostas no teste de compreensão.

A princípio, previmos para o grupo SP que, se os participantes fossem leitores proficientes, conseguiriam, através de uma prosódia implícita, recuperar mentalmente as variações melódicas incitadas pelo processo dialógico do texto, proporcionando uma projeção dessa marcação na leitura em voz alta. Assim, mesmo que os participantes não tivessem no texto uma marcação gráfica convencional, isso não influenciaria significativamente na compreensão do texto. Esperávamos também que, devido à tarefa de ter que pontuar o texto após a leitura, os participantes desse grupo teriam sua atenção comprometida pela tarefa de pontuar e poderiam apresentar mais erros no teste de compreensão, principalmente em relação à 
retenção de palavras. Afinal, a preocupação seria segmentar as orações e dar sentido ao texto. Quanto ao grupo $\mathrm{CP}$, se os participantes fossem leitores proficientes, interpretariam prosodicamente as marcas gráficas na leitura em voz alta e compreenderiam 0 texto sem problemas, obtendo melhores resultados do que os participantes do grupo SP.

Nesse sentido, para esse experimento, a variável independente era a ausência/presença de pontuação, já que pretendíamos verificar se a ausência dos sinais de pontuação influenciaria na leitura em voz alta e na compreensão dos participantes. Já as variáveis dependentes que mensuramos foram: (i) a quantidade de MGs (marcações gráficas) e MPs (marcações prosódicas) na leitura e (ii) a quantidade de erros no teste de compreensão.

\subsection{Resultados da tarefa de leitura}

Para iniciar a análise, comparamos a MG do texto original com a marcação realizada pelos participantes do grupo SP, contabilizamos o total de MGs presentes no texto-estímulo e dividimos essas marcações em coincidentes, diferentes e excedentes. As coincidentes compreendem as marcações gráficas compatíveis com os sinais de pontuação do texto original. As diferentes, por sua vez, são as marcas gráficas não compatíveis - por exemplo, quando o texto original apresentava um ponto final e o leitor do grupo SP marcou uma vírgula no mesmo local - e as excedentes são as ocorrências de marcas em locais em que não havia sinal de pontuação no texto original. Além disso, contabilizamos também as marcações ausentes, quando havia o sinal gráfico no texto original, mas não era feita nenhuma marcação pelos participantes.

Do total de marcações esperadas (39 sinais de pontuação $X 11$ participantes $=429$ marcações), $61 \%$ foram marcadas (264 marcações feitas) e 39\% estavam ausentes (165 marcações ausentes). Já do total de marcas realizadas (264 marcações), 74\% foram coincidentes (195 marcações), 22\% diferentes
(59 marcações) e 4\% excedentes (10 marcações). Os casos de marcações diferentes ocorreram, em geral, quando se esperava um ponto final e a marcação foi uma vírgula, ou seja, a vírgula foi usada no final de uma oração ou parágrafo, como é o caso do excerto (1) que representa a marcação gráfica de 4 participantes do grupo SP:

(1) [um menino de nove anos foi agredido na saída da escola por colegas de classe e teve de ser hospitalizado,] I [ ele teve uma lesão na coluna cervical e vai precisar de um colete ortopédico por uns dias,] I

Já os casos de marcações excedentes se caracterizaram, principalmente, pelo uso da vírgula em fronteiras de sujeito longo com um verbo. Vejamos os excertos a seguir:

(2) [um menino de nove anos,] I [foi agredido na saída da escola por colegas de classe e teve de ser hospitalizado.]

(3) [a secretaria de educação do estado,] I [disse que foi aberta uma apuração preliminar para averiguar a denúncia de agressão entre os alunos da escola.]

Os excertos (2) e (3) são exemplos de marcações excedentes realizadas por três participantes do grupo SP. São considerados desvios pela gramática normativa, conforme Cunha e Cintra (2001) que justificam essa proibição através da seguinte afirmação: "os termos essenciais e integrantes ligam-se uns com os outros sem pausa; não devem assim ser separados por vírgula" (CUNHA; CINTRA, 2001, p.650). Contudo, como os sujeitos são extensos, dependendo do leitor e do estilo de fala, uma pausa para respiração pode ser realizada após o sujeito longo. E ainda, de acordo com a teoria fonológica de Nespor e Vogel (2007), um sujeito longo pode ser caracterizado prosodicamente como um sintagma entoacional. Assim, o ambiente é propício para uma pausa, mas não significa que deve haver vírgula, já que nem sempre há isomorfismo entre ocorrências de pausa e pontuação, assim como nem sempre há isomorfismo entre os constituintes sintáticos e os prosódicos. 
Quanto às marcações ausentes, os casos mais recorrentes foram em locais em que havia um adjunto adverbial e entre orações subordinadas. Sinalizamos as ausências com o símbolo "_" nos trechos que mais se destacaram:

(4) [após o ocorrido] _ [o garoto foi para casa]

\section{(5) [se for comprovada a participação dos}

meninos] _ [eles poderão cumprir medidas socioeducativas previstas no estatuto da criança e do adolescente]

A ausência de pontuação nos excertos (4) e (5) é considerada inadequada por algumas gramáticas normativas. No primeiro excerto, há um adjunto adverbial de tempo deslocado para o início da oração, "após o ocorrido", e de acordo com Bechara (2009), a vírgula deve ser usada para isolar o adjunto adverbial antecipado. No entanto, 7 de 11 participantes não marcaram a vírgula neste caso. Cegala (2005) também descreve essa regra, mas faz a ressalva de que se o adjunto adverbial for breve, a vírgula é dispensada.

Quanto ao segundo caso, oração subordinada condicional, a não marcação foi comum também a 7 de 11 participantes. Sobre isso, verificamos que as gramáticas analisadas não fazem referência direta ao uso da vírgula para separar a oração subordinada condicional ou a oração subordinada conformativa da oração principal. Geralmente o uso entre orações se refere às orações subordinadas adjetivas explicativas e às orações subordinadas adverbiais, principalmente quando antepostas à principal.

Desse modo, a gramática prioriza alguns casos e não estende a regra aos outros tipos de oração subordinada, o que pode gerar dúvidas aos escreventes/aprendizes. Nota-se então flutuação nas descrições das regras, as quais podem comprometer o sucesso do aprendiz quanto ao uso dos sinais de pontuação nos textos escritos.

Para observar se a marcação equivocada ou ausência de pontuação no texto estímulo influenciaria a leitura, comparamos as MGs feitas pelos informantes no texto-estímulo com as MPs realizadas durante a leitura. Analisamos as gravações das leituras com o auxílio do programa de análises acústicas Praat, marcando nos espectrogramas as pausas realizadas nos enunciados e os tons de fronteiras entre os sintagmas, a fim de contabilizar o número de pausas realizadas por cada participante e verificar se a pausa feita ou o tom realizado correspondiam a alguma marcação gráfica presente no texto-estímulo.

Através da análise dos dados de duração para os dois grupos, percebemos que não houve muita diferença em relação ao número de pausas, uma média de 35 pausas silenciosas por participante. Já em relação aos tempos de leitura, em 7 de 11 participantes do grupo $\mathrm{CP}$, os tempos são abaixo de 100 segundos, enquanto 8 de 11 participantes do grupo SP realizaram o tempo acima de 100 segundos. Os dados indicam que as leituras do grupo $\mathrm{CP}$ foram, em geral, um pouco mais rápidas quando comparadas com o grupo SP. Isso sugere que os participantes do grupo CP, salvo algumas exceções, por lerem o texto já pontuado e formatado em parágrafos, obtiveram maior velocidade de leitura.

$\mathrm{Na}$ análise entoacional, observamos os tons de fronteira realizados durante a leitura dos participantes dos dois grupos. Adotamos a notação entoacional conhecida como ToBI (Tones and Break Indices) (LADD, 1996). Nesta notação, tons de fronteira são tons simples representados por $\mathrm{H} \%$ (alto) ou $\mathrm{L} \%$ (baixo). Esses tipos de tons estão associados com a porção localizada ao final de um sintagma entoacional em diversas línguas, inclusive no Português. Desse modo, o tom de fronteira se associa fonologicamente ao limite de uma frase, ou limites de constituintes prosódicos, e não se associa à marcação de proeminência.

Para observar como se dá a relação entre sinais de pontuação e tons de fronteira, observamos a atribuição dos tons quando havia uma fronteira marcada pelo sinal de pontuação (ou que poderia ser marcada de acordo com o texto com a pontuação original). Como esperado, percebemos que a fronteira entre um e outro sintagma entoacional nem sempre é marcada por pausa, pois pode ser marcada apenas pelo tom de fronteira alto $\mathrm{H} \%$, por exemplo. Além disso, pudemos notar no espectrograma que a 
fronteira de sintagma entoacional que se localiza no início de uma sentença ou no meio é marcada, na maioria das vezes, por uma subida do pitch e por um tom fronteira $\mathrm{H} \%$. Já a fronteira de sintagma entoacional final é marcada quase sempre por pausa e pela descida do pitch e pelo tom fronteira $L \%$.

A fonologia prosódica e a fonologia entoacional pressupõem uma relação entre contorno entoacional, organização prosódica e estrutura sintática. Desse modo, com o objetivo de verificar se há uma regularidade prosódica entre uso do sinal de pontuação, função do sinal (FS) e a realização dos tons de fronteira, enumeramos os sinais de pontuação e os agrupamos de acordo com a sua função sintática. Deixamos fora da análise o ponto final do texto por ser um sinal que não faria muita diferença para a análise e dividimos então os 38 sinais contidos no texto original em: 10 pontos finais de período (PFPE), 4 pontos finais de parágrafo (PFPA), 9 vírgulas de apostos (VA), 5 vírgulas de termos deslocados para o início da frase (VTDI), 4 vírgulas de termos intercalados no meio ou no final da frase (VTIMF), 1 vírgula de oração coordenada sindética adversativa (VOCSA), 1 vírgula de oração subordinada condicional deslocada (VOSCD), 2 vírgulas de orações intercaladas (VOI), 1 vírgula de vocativo (VV) e 1 dois pontos de inserção da voz do outro (DP). Em seguida, para cada uma dessas categorias de função sintática, calculamos a porcentagem para o número de ocorrências de tons de fronteiras $\mathrm{H} \%$ e $\mathrm{L} \%$ de cada grupo (CP e SP) e comparamos com a porcentagem de MGs do texto estímulo. No caso do grupo CP, como a marcação era a original, apenas contabilizamos a MP produzida e ausente. Já no caso do grupo SP, contabilizamos a porcentagem da marcação gráfica representada (MGR) e marcação gráfica ausente (MGA) e da MP em tons $L \%$ e $\mathrm{H} \%$. Vejamos a tabela 1 que representa os resultados dessa tarefa de produção.

\begin{tabular}{|c|c|c|c|c|c|c|c|}
\hline FS & Grupo & MGR & MGR & MGA & MP (L\%) & IAP (H\%) & MPA \\
\hline PFPA & $\mathrm{CP}$ & & & & $100 \%$ & $0 \%$ & $0 \%$ \\
\hline PFPA & SP & Ponto $62,5 \%$ & Vírgula $30 \%$ & $7,5 \%$ & $95 \%$ & $5 \%$ & $0 \%$ \\
\hline PFPE & $\mathrm{CP}$ & & & & $100 \%$ & $0 \%$ & $0 \%$ \\
\hline PFPE & SP & Ponto $53 \%$ & Vírgula $36 \%$ & $11 \%$ & $96 \%$ & $4 \%$ & $0 \%$ \\
\hline VA & $\mathrm{CP}$ & & & & $28 \%$ & $68 \%$ & $0 \%$ \\
\hline VA & SP & \multicolumn{2}{|c|}{ Vírgula $33,6 \%$} & $66,4 \%$ & $27,7 \%$ & $59 \%$ & $13,3 \%$ \\
\hline VTDI & $\mathrm{CP}$ & & & & $2 \%$ & $98 \%$ & $4 \%$ \\
\hline VTDI & SP & \multicolumn{2}{|c|}{ Vírgula $30 \%$} & $70 \%$ & $4 \%$ & $94 \%$ & $2 \%$ \\
\hline VTIMF & $\mathrm{CP}$ & & & & $12 \%$ & $80 \%$ & $8 \%$ \\
\hline VTIMF & SP & \multicolumn{2}{|c|}{ Vírgula $25 \%$} & $75 \%$ & $5 \%$ & $40 \%$ & $55 \%$ \\
\hline VOCSA & $\mathrm{CP}$ & & & & $70 \%$ & $30 \%$ & $0 \%$ \\
\hline VOCSA & SP & \multicolumn{2}{|c|}{ Virgula $30 \%$} & $70 \%$ & $30 \%$ & $50 \%$ & $20 \%$ \\
\hline VoSCD & $\mathrm{CP}$ & & & & $0 \%$ & $100 \%$ & $0 \%$ \\
\hline VOSCD & SP & \multicolumn{2}{|c|}{ Vírgula $20 \%$} & $80 \%$ & $0 \%$ & $80 \%$ & $20 \%$ \\
\hline VV & $\mathrm{CP}$ & & & & $0 \%$ & $100 \%$ & $0 \%$ \\
\hline VV & SP & \multicolumn{2}{|c|}{ Virgula $40 \%$} & $60 \%$ & $10 \%$ & $80 \%$ & $10 \%$ \\
\hline VOI & $\mathrm{CP}$ & & & & $0 \%$ & $100 \%$ & $0 \%$ \\
\hline VOI & $\mathrm{SP}$ & \multicolumn{2}{|c|}{ Vírgula $40 \%$} & $60 \%$ & 10 & $85 \%$ & $5 \%$ \\
\hline DP & $\mathrm{CP}$ & & & & $100 \%$ & $0 \%$ & $0 \%$ \\
\hline DP & SP & \multicolumn{2}{|c|}{ Dois Pontos $60 \%$} & $40 \%$ & $90 \%$ & $0 \%$ & $10 \%$ \\
\hline
\end{tabular}

Tabela 1: Porcentagem de MGs do grupo SP e porcentagem de MPs de cada grupo

De acordo com a teoria prosódica e resultados de alguns estudos realizados no Português Brasileiro (SONCIN; TENANI, 2015; SERRA, 2009), a separação entre orações ou termos feita por vírgulas na escrita corresponderia ao tom de fronteira $\mathrm{H} \%$ na leitura. Isso porque o tom $\mathrm{H} \%$ é um tom continuativo, dando ao leitor a pista de que o enunciado não terminou. Já os finais de enunciado, marcados pelo ponto na escrita corresponderiam ao tom de? fronteira L\%. Conforme esperado, ao comparar os tons de fronteira com os sinais gráficos dos textosestímulos dos grupos CP e SP, na maioria dos casos, os tons $\mathrm{H} \%$ foram associados aos sinais de pontuação continuativos, como vírgulas que separam termos e orações de um mesmo período. Já nos finais de período e parágrafo, o tom de fronteira $L \%$ foi predominantemente associado ao sinal de ponto final de período ou o de parágrafo. O grupo SP, apesar do elevado número de MGAs (39\%), durante a leitura, marcou prosodicamente com pausa e/ou tom de fronteira em $89 \%$ das fronteiras que poderiam ser 
marcadas graficamente de acordo com a pontuação esperada (372 marcações prosódicas de 418 possíveis). Em relação à duração das pausas, percebemos também que, em geral, quando há marca gráfica a pausa é maior do que quando ela está ausente. Dois participantes do grupo SP realizaram pausas mais curtas, quando comparadas com os outros participantes. Das 38 marcas gráficas esperadas para cada participante, os dois participantes em questão fizeram apenas 14 marcações cada no texto escrito, deixando de marcar muitas vírgulas. Mesmo com pausas curtas, os participantes, na leitura em voz alta, apesar de realizar poucas marcas gráficas no texto escrito, realizam a maioria das entoações esperadas. Assim, a pausa curta parece estar associada à ausência de marca gráfica.

Outro dado interessante em relação à atribuição de tons é o fato de alguns leitores do grupo SP usarem $\mathrm{H} \%$, onde a maioria do grupo CP utilizou L\%, como o caso das adversativas e de alguns pontos, ou o contrário, L\% onde se esperava um $\mathrm{H} \%$, como no caso de vocativo, termos deslocados para o início da frase, entre outros. Percebemos que as entoações que desviavam do padrão ocorreram geralmente quando a fronteira não foi marcada por um sinal de pontuação. O participante 20, por exemplo, apresentou uma entoação mais aleatória em alguns trechos, marcando um final de enunciado (não marcado graficamente por ele) com tom ascendente e pausa curta. Observamos também que houve enganos na segmentação dos enunciados durante a leitura desse participante devido à ausência de pontuação. Percebe-se em um determinado trecho do texto, a ocorrência de um efeito Garden Path - o chamado efeito labirinto (DILINGER, 1992) - o qual parece ter ocorrido porque o participante não fez uma marcação gráfica adequada para sinalizar um vocativo.

A seguir, encontra-se a representação desse trecho no espectrograma.

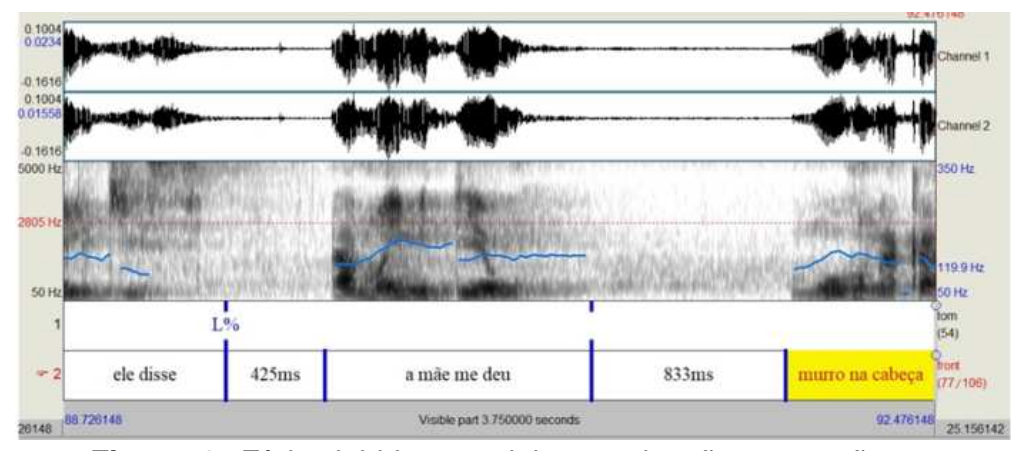

Figura 2: Efeito labirinto na leitura pela não marcação prosódica do vocativo "ah, mãe" - Info 20_SP

Percebe-se na figura 2 que, durante a leitura, 0 participante interpreta o vocativo como sujeito. Ao perceber que sua interpretação foi equivocada, ele faz uma pausa longa (833 milissegundos) e continua a leitura. Apesar de o participante não reler o trecho após a constatação do equívoco, acreditamos que a pausa longa sinaliza que o participante reestruturou 0 enunciado para continuar o processamento. Sugerimos que tal fato pode estar relacionado ao alto índice de ausência de marca gráfica no textoestímulo. Além disso, esse dado parece indicar que a prosódia implícita é mais atuante com leitores proficientes em leitura e escrita, já que os dados do participante indicam que ele tem pouco domínio de leitura e escrita. Assim, além da ausência de pontuação, a ausência de proficiência compromete a marcação prosódica na leitura.

Os resultados sugerem que alguns participantes empregaram bem o seu conhecimento internalizado de organização prosódica, semântica e discursiva ao realizar a entoação na leitura em voz alta, mas não souberam como marcar graficamente através dos sinais de pontuação, como podemos perceber pelo índice de marcação de vírgula para representar o ponto final de período (36\%) e de ponto final de parágrafo (30\%), além dos elevados índices (acima de 60\%) de MGA para as marcações de vírgulas. Já aqueles que não têm muita prática com leitura e escrita apresentaram dificuldades tanto na MG quanto na MP na leitura em voz alta.

\subsection{Resultados do teste de compreensão}


A tarefa de compreensão foi elaborada a partir de 24 itens conforme Salasoo (1986) e adaptado de Leite (2012). As 12 primeiras questões estão no nível da palavra, sendo 6 não pertencentes à ideia central do texto, ou seja, fora da ideia central $(F I)$ e as outras 6 pertencentes à ideia central do texto, ou seja, dentro da ideia central (DI). Cada grupo de questões foi composto por 3 alternativas verdadeiras e 3 falsas. Desse modo, foram feitas perguntas da seguinte forma: "A palavra X ocorreu no texto?". As outras 12 questões eram proposições de nível inferencial e deveriam ser julgadas como verdadeiras ou falsas, sendo 6 afirmativas sobre informações que estavam fora da ideia central do texto $(F I)$ e 6 sobre informações que faziam parte da ideia central do texto (DI). Para cada um desses grupos de 6 itens, havia 3 verdadeiras (informações que estavam no texto) e 3 falsas (informações que não estavam no texto). Determinamos que a ideia central do texto é composta pelas informações principais em relação à agressão e suas causas. Outras informações secundárias em relação ao fato foram, portanto, consideradas fora da ideia central do texto.

Ao comparar os dados entre os grupos, verificamos que não houve diferença na taxa de erro/acertos para cada nível de questões. Obteve-se no nível de palavra $30,3 \%$ de erros em ambos os grupos e no nível de proposições aproximadamente $16 \%$ de erros para ambos os grupos. Tal resultado contrariou nossa expectativa, pois esperávamos que o grupo SP apresentasse maior taxa de erro no teste de compreensão, devido à sobrecarga para a memória de trabalho pela realização da tarefa de pontuar o texto lido.

Verificou-se também que o nível que apresentou mais erros foi o da palavra para ambos os grupos, inclusive a mesma taxa de erros, o que sugere que os leitores têm mais dificuldades de se lembrarem das palavras que leram e menos dificuldade para se lembrarem das informações. Isso indica que o leitor lê globalmente sem se atentar detalhadamente às palavras do texto. Além disso, pudemos perceber, de acordo com os dados, que o tipo de estímulo da leitura (texto pontuado ou não) não foi relevante para a compreensão dos participantes desta pesquisa.

Ainda para cada nível, foram observados os resultados para cada condição: $\mathrm{DI}(-) \mathrm{DI}(+), \mathrm{Fl}(-) \mathrm{Fl}(+)$. Contudo, houve pouca diferença entre os grupos para as questões de nível lexical em cada condição. A maior diferença ocorreu para a primeira condição DI(), palavras pertencentes à ideia central, porém ausentes no texto. O grupo SP apresentou maior taxa de erros (48,5\%) do que o grupo CP $(36,4 \%)$, o que era esperado, porém apresentou a mesma taxa de erro que o grupo CP para a condição $\mathrm{DI}(+)$, palavras dentro da ideia central do texto, presentes no texto $(9,1 \%)$ e menores taxas de erro nas condições $\mathrm{FI}(-)$ palavras fora da ideia central ausentes no texto e $\mathrm{FI}(+)$, palavras fora da ideia central do texto mas presentes no texto. Tais resultados não eram esperados, porque como os participantes deste grupo leram o texto sem pontuação, esperávamos que sua atenção se voltasse para a construção do sentido do texto e para a marcação gráfica e por isso a atenção nas palavras presentes no texto seria menor. No entanto, parece que justamente por estarem muito atentos em construir sentido para o texto e pontuar 0 texto, a memorização das palavras foi melhor para o grupo SP do que a do grupo CP que apenas tinha que ler o texto já pontuado.

$\mathrm{Da}$ mesma forma como aconteceu nos resultados das respostas do nível lexical, o grupo SP também apresentou taxas de erros iguais ou menores que as taxas do grupo $\mathrm{CP}$, o que fortalece a nossa hipótese de análise descrita acima. Ambos os grupos erraram 27,3\% das afirmações DI(-), mas acertaram todas as afirmações $\mathrm{DI}(+)$, o que é esperado já que se lembrar do que é verdadeiro, isto é, da informação que está presente no texto, é mais fácil do que se lembrar do que é falso ou não está presente no texto. Porém, como o grupo SP leu mais atentamente, a taxa de erros para $\mathrm{FI}(-)$ foi menor $(18,2 \%)$ que a do grupo CP $(24,2 \%)$. Já o mesmo não ocorreu para a condição $\mathrm{FI}(+)$ em que a taxa de erro do grupo CP $(12,1 \%)$ foi menor que a do grupo SP $(21,2 \%)$.

Embora a porcentagem de erros no nível da palavra tenha sido em torno de $30 \%$ para o grupo SP 
(assim como para o grupo $\mathrm{CP}$ ), esse resultado não parece sinalizar dificuldades de compreensão do texto pelos participantes, já que os participantes responderam satisfatoriamente as questões de nível inferencial.

Em suma, os resultados do experimento indicam que os sinais de pontuação sinalizam as características prosódicas que são interpretadas na leitura em voz alta, em consonância com Cagliari (1989), conforme percebido na análise dos dados do grupo CP. Além disso, os casos do grupo SP em que uma marca foi realizada prosodicamente, mesmo estando ausente graficamente, contribuem como evidências para a hipótese da prosódia implícita de Fodor (2005) e também para a teoria de Nespor e Vogel (2007) a respeito da organização prosódica hierárquica mental. Vimos também que a ausência de alguma marca de pontuação ou a presença de uma marca inadequada parece influenciar a produção. No entanto, não parece influenciar a compreensão global, já que praticamente não houve diferença nos resultados da tarefa de compreensão entre os grupos.

\section{Considerações Finais}

Neste artigo buscamos investigar a relação entre pontuação, leitura em voz alta e compreensão. Os resultados apontam que a ausência ou uso inadequado de sinais de pontuação podem comprometer a fluidez da leitura, porém, de acordo com os nossos dados, parece não afetar significativamente a compreensão. Mesmo quando no texto-estímulo não havia marca gráfica que representasse a segmentação dos enunciados, a prosódia implícita guiou a segmentação e a organização dos constituintes prosódicos e sintáticos, permitindo o processamento linguístico.

Os resultados desta pesquisa refletem lacunas das práticas de ensino dos sinais de pontuação na educação básica, principalmente em relação ao uso da vírgula. Tal fato parece estar relacionado com a forma de abordagem do assunto que é pautada nos manuais de gramática, baseada em regras e desvinculada das práticas de leitura. Desse modo, prioriza-se o conhecimento explícito normativo ao invés de acionar o conhecimento internalizado, descritivo e reflexivo para um efetivo domínio do conteúdo.

Portanto, sugerimos que, para resolver esse impasse, o professor deve considerar fundamental em sua didática a comparação e a reflexão entre as normas prescritas pelos manuais de gramática e os usos dos sinais de pontuação na escrita dos alunos. Durante esse processo, torna-se necessário, também, explorar as características prosódicas dessas marcas através da leitura em voz alta e correlacioná-las com os diferentes sinais de pontuação. Além disso, a prática, a exposição ao input, ou seja, o treino da leitura em voz alta deve ser incentivado durante todo o período escolar, no intuito de despertar o gosto pela leitura e garantir a formação de leitores competentes e expressivos. Enfim, acreditamos também que o conhecimento sobre prosódia, ao lado da sintaxe, como parte estruturante do processo de pontuar um texto, deva ser mais difundido nos manuais de gramática, nos livros didáticos e nos cursos de licenciatura, a fim de preparar os docentes para a realização de um trabalho menos normativo e mais reflexivo.

\section{Referências}

BECHARA, Evanildo. Moderna gramática portuguesa. 37. ed. rev., ampl. e atual. conforme o novo Acordo Ortográfico. Rio de Janeiro: Nova Fronteira. 2009.

BERNARDES, Ana Cristina de Aguiar. Pontuando alguns intervalos da pontuação. Tese (Doutorado em Linguística). Psicolinguística. Campinas, SP: [s.n.]. 2002.

BOERSMA, Paul; WEENICK, David. PRAAT: doing phonetics by computer (version: 5.3.53), 2013. Disponível em: <http://www.praat.org/>.

BORBA, Valquíria Claudete Machado; PEREIRA, Monalisa dos Reis Aguiar; SANTOS, Adelino Pereira. Leitura e Escritura: processos cognitivos, aprendizagem e formação de professores Revista da FAEEBA - Educação e Contemporaneidade, Salvador, v. 23, n. 41, p. 19-26, jan./jun. 2014. Disponível em: <https://www.revistas.uneb.br/index.php/faeeba/art icle/viewFile/820/578> Acesso em 09/09/2017. 
CAGLIARI, Luiz Carlos. Marcadores prosódicos na escrita. In: Seminário do grupo de Estudos Linguísticos, 18, 1989, Lorena. Anais do XVIII Seminário do Gel. Lorena: Grupo de Estudos Lingüísticos de São Paulo, 1989. p. 195-203.

CEGALLA, Domingos Paschoal. Novíssima gramática da língua portuguesa. 46. ed. São Paulo: Companhia Editora Nacional, 2005.

CUNHA, Celso Ferreira; CINTRA, Luís Filipe Lindley. Nova Gramatica do Português. Contemporâneo. Rio de Janeiro: Nova Fronteira, 3a ed..2001.

DILLIGER, Mike. Parsing Sintático. Boletim da Abralin no 13, p.30-42, 1992.

FODOR, Janet. A psicolinguística não pode escapar da prosódia. In: MAIA, Marcus. e FINGER, Ingrid. Processamento da linguagem. Série Investigações em Psicolingüística. GT de Psicolingüística da ANPOLL. EDUCAT, Pelotas, 2005. p.131-162.

FONSECA, Aline. Alves. Pistas prosódicas e o processamento de sentenças ambíguas do tipo "SN1_V_SN2_Atributo" do Português Brasileiro. Dissertação (mestrado em Estudos Linguísticos). Linha Organização Sonora da Comunicação Humana. Belo Horizonte, Universidade Federal de Minas Gerais, 2008.

FORSTER, Jonathan; FORSTER, Kenneth. DMDX Display Software. 2002. Disponível em: $<$ http://www.u.arizona.edu/ kforster/dmdx/dmdx.ht $\mathrm{m}>$.

FRAZIER, Lyn. On comprehending sentences: syntactic parsing strategies. Doctoral Dissertation. Connecticut: University of Massachusetts, 1979.

G1. Edição São Paulo - NOTÍCIAS - Menino é agredido por colegas em escola no interior de $S P$ e vai parar no hospital. Disponível em: <http://g1.globo.com/noticias/saopaulo/0,,mul1310 133-5605,00-

menino+e+agredido+por+colegas+em+escola+no +interior+de+sp+e+vai+parar+no+ho.html.> Acesso em: 07/08/2017.

GABRIEL, Rosângela; MORAIS, José; KOLINSKY, Régine. A aprendizagem da leitura e suas implicações sobre a memória e a cognição. Ilha do Desterro [online]. 2016, vol.69, n.1, pp.61-78.
KLEIMAN, Angela. Oficina de Leitura: Teoria e Prática. 9. ed. Campinas: Pontes, 2008.

LADD, Robert. Intonational Phonology. Cambridge University Press, 1996, p. 87-130.

LEITE, Camila Tavares. A relação entre a compreensão e os aspectos prosódicos na leitura em voz alta de falantes do PE e do PB. Tese (doutorado em Linguística Teórica e Descritiva). Organização Sonora da Comunicação Humana. Faculdade de Letras, UFMG, Belo Horizonte. 2012.

NESPOR, Marina; VOGEL, Irene. Prosodic Phonology: with a new foreword. Berlim: Mouton de Gruyter. 2007.

PACHECO, Vera. Investigação fonético-acústico e experimental dos sinais de pontuação enquanto marcadores prosódicos. Dissertação (mestrado em Lingüística). 132f. Instituto de Estudos da Linguagem, Unicamp, Campinas, 2003.

ROCHA LIMA, Carlos Henrique. Gramática normativa da língua portuguesa. Rio de Janeiro,1964.

SALASOO, Aita. Cognitive processing in oral and silent reading comprehension.

Reading Research Quarterly, v.21 n.1. (Winter, 1986) p. 58-69. 2007. Disponível em: http://links.jstor.org/sici?sici=00340553\%28198624\%2921\%3A1\%3C59\%3ACPIOAS \%3E2.0.CO\%3B20]

SERRA, Carolina Ribeiro. Realização e percepção de fronteiras prosódicas no Português do Brasil: Fala espontânea e Leitura. Rio de Janeiro: UFRJ. Tese de Doutorado. 2009.

SONCIN, Geovana; TENANI, Luciani. Emprego de vírgulas e prosódia do Português Brasileiro: aspectos teórico-analíticos e implicações didáticas. Filologia e Linguística Portuguesa, São Paulo, v. 17, n. 2, p. 473-493, 2015.

\section{COMO CITAR ESSE ARTIGO}

ALMEIDA, Simone Aparecida; FONSECA, Aline Alves. A RELAÇÃO ENTRE OS SINAIS DE PONTUAÇÃO E O PROCESSAMENTO DE LEITURA DE ALUNOS CONCLUINTES DO ENSINO MÉDIO. Signo, Santa Cruz do Sul, v. 43, n. 77, jul. 2018. ISSN 1982-2014. Disponível em: <https://online.unisc.br/seer/index.php/signo/article/view/11534>. Acesso em: doi: http://dx.doi.org/10.17058/signo.v43i77.11534. 